\title{
Benthic disturbance due to fish farming analyzed under different levels of taxonomic resolution
}

\author{
Ioannis Karakassis*, Eleni Hatziyanni \\ Institute of Marine Biology of Crete, PO Box 2214, 71003 Heraklion, Crete, Greece
}

\begin{abstract}
The multivariate patterns resulting from analyses of macrobenthic abundance data at different taxonomic levels are compared among different sites subject to a varying degree of disturbance due to sea bream and sea bass farming in 3 Mediterranean coastal areas. The results confirmed that there is little information loss with lower taxonomic resolution but showed no relationship between the level of pollution in an area and the correlations between similarity matrices at the species level and those derived from analysis of higher taxa. A cost/benefit ratio analysis, used for the selection of the optimal taxonomic level for the analysis of macrofaunal data, showed that the family level gives the best balance between precision of the results and decrease in taxonomic effort, therefore indicating that monitoring of fish farming effects could be carried out at the family level.
\end{abstract}

KEY WORDS: Macrobenthos monitoring - Taxonomic resolution . Multivariate analysis . Disturbance $\cdot$ Aquaculture $\cdot$ Mediterranean $\cdot$ Aegean Sea · Ionian Sea

Resale or republication not permitted without written consent of the publisher

\section{INTRODUCTION}

Analysis of benthic data at lower levels of taxonomic discrimination has been proven to be an efficient method for detecting environmental change in strong environmental gradients (Warwick 1988a,b, Ferraro \& Cole 1990). It has also been shown that in macrofaunal studies surprisingly little information is lost with decreasing taxonomic resolution (Somerfield \& Clarke 1995, Olsgard et al. 1997, Rumohr \& Karakassis 1999).

In a recent study Olsgard et al. (1998) analyzed data from 20 sites from the northern part of the North Sea and the coastal waters of Norway (latitudinal range: 56 to $62^{\circ} \mathrm{N}$ ) and found that faunal patterns for the various taxonomic levels become more similar with increasing disturbance. Although Olsgard et al. (1998) did not claim global application of their findings, it is quite reasonable to test if identical patterns are observed under different conditions.

Disturbance effects of fish farming on the seabed are quite well known for salmonids (Brown et al. 1987,

*E-mail: jkarak@imbc.gr
Gowen \& Bradbury 1987, Weston 1990, Iwama 1991) as well as for the Mediterranean sea bream and sea bass farming industry (Karakassis et al. 1998, 1999, 2000). These effects are in general quite similar to the empirical model of macrobenthic succession along gradients of organic enrichment described by Pearson \& Rosenberg (1978).

The aim of the present paper was to investigate the effect of decreasing taxonomic resolution on the information obtained through multivariate analysis in the context of mariculture impact on Mediterranean benthic communities. The data set used (Karakassis et al. 2000) comes from 3 well-studied areas which seemed to span a wide range of benthic enrichment impacts, from very severe to almost negligible, due to differences in local ecological conditions. Therefore this data set seems quite appropriate for this type of study. Although the spatial scales involved were different to those used in Olsgard et al. (1998) (which is a consequence of the spatial extent of fish farming effects) similar methodology was used in order to get comparable results and therefore to explore the potential for expanding their conclusions to different geographic areas and different degrees of disturbance. A cost/ 
benefit index is introduced for the selection of the most appropriate taxonomic level for monitoring the ecological change introduced by fish farming.

\section{MATERIALS AND METHODS}

Three spatio-temporal data sets were used for 3 fish farming areas, henceforth referred to as Cephalonia, Ithaki and Sounion. Macrofaunal samples were taken at a distance of $0,5,10$ and $25 \mathrm{~m}$ from the cages as well as at a control site located upstream from the main direction of the water current. All 3 areas were sampled during July and November 1995 and April 1996. Data from the replicates (3 to 5) taken at each station were pooled as in Olsgard et al. (1998).

In previous papers detailed data have been reported for impacts on geochemical variables (Karakassis et al. 1998, in press) and on the structure of macrofaunal assemblages (Karakassis et al. 1999, in press) in Cephalonia, Ithaki and Sounion. Impacts on nutrient and plankton dynamics at these 3 fish farming sites have been investigated by Pitta et al. (1999).

A brief description summarizing the information reported by Karakassis et al. (in press) on the type of impacts on the seabed beneath (and the area close to) the cages is given in Table 1. The fish farm in Cephalonia Bay showed typical signs of disturbance due to organic enrichment with low macrofaunal abundance dominated by the Capitella complex (Capitella spp.). The 2 coarse sediment sites showed high macrofaunal abundance (10 times more than the respective control sites) dominated by Capitella spp. in Ithaki and by the polychaetes Protodorvillea kefersteini and Cirrophorus lyra in Sounion. Using the classification scheme of Pearson \& Rosenberg (1978), the macrofaunal community under the cages at Cephalonia could be considered typical of the 'polluted' zone, the community at Ithaki as 'early transitory' zone, with a peak of opportunistic species, whereas macrofaunal assemblages at Sounion seemed to correspond to the late 'transitory zone' (i.e. closer to the 'normal' side of the gradient). The associated geochemical variables, and particularly redox potential and total organic carbon (TOC), confirmed the general pattern showing higher enrichment and low Eh in Cephalonia, almost negligible effects in Sounion and intermediate ones in Ithaki.

For each of the 3 fish farming areas, species-abundance data of all macrobenthic samples were aggregated to the levels of genus, family, order, class and phylum, and similarities were calculated by means of the Bray-Curtis similarity index (Bray \& Curtis 1957). This analysis was repeated using different types of transformation (none, square root, 4th root, $\log [x+1]$, presence/absence) in order to compare the effects of transformation to those of the differences in taxonomic resolution on the results of the multivariate analysis as previously done by Olsgard et al. (1997, 1998). The 30 similarity matrices obtained for each area (6 taxonomic levels $\times 5$ transformations) were compared using the non-parametric Spearman rank correlation coefficient. For each area the intermatrix rank correlation values (among all taxonomic levels and types of transformation) were used for a 'second stage' ordination according to the approach described in Somerfield \& Clarke (1995) using non-metric multidimensional scaling (MDS; Field et al. 1982).

A cost/benefit ratio was calculated for each data set in order to objectively select the taxonomic level with the minimal loss of information and the least taxonomic effort according to the formula:

$$
C B_{L}=\frac{\left(1-r_{L}\right)}{\frac{S-t_{L}}{S}}
$$

$C B_{L}$ is the cost/benefit ratio at taxonomic level $L, r_{L}$ the Spearman correlation coefficient between taxonomic level $L$ and species level, $t_{L}$ the number of taxa present at taxonomic level $L$ and $S$ the number of species.

This numerator (and therefore the ratio) becomes 0 when the multivariate pattern obtained through the analysis at taxonomic level $L$ is highly correlated $\left(r_{L}=\right.$ 1.0) to that obtained through the analysis at the species level, i.e. when information loss $\left(1-r_{L}\right)$ becomes 0 . The denominator of the formula (the benefit) is the proportion of decrease in the categories (taxa) that need to be identified during the analysis in comparison to the number of species (i.e. the highest level of taxonomic

Table 1. Summary of the effects up to $10 \mathrm{~m}$ from the edge of the cages in comparison to the respective control sites

\begin{tabular}{|lccc|}
\hline & Cephalonia & Ithaki & Sounion \\
\hline Macrofaunal diversity & $<$ & $<$ & $<$ \\
Macrofaunal abundance & $<$ & $>$ & $>$ \\
Macrofaunal biomass & $<$ & $>10 \times$ & $>10 \times$ \\
Capitella spp. & Dominant & Dominant & Present \\
Protodorvillea kefersteini \& & & & \\
Cirrophorus lyra & Abundant & Present & Dominant \\
Tharyx heterochaeta & Absent & Absent & Absent \\
Redox potential & $<<$ & $\approx /<$ & $\approx$ \\
ATP & $10 \times$ & $10 \times$ & $2 \times$ \\
TOC & $2 \times$ & $2 \times$ & $=$ \\
TON & $2 \times$ & $2 \times$ & $=$ \\
Sediment type & Muddy sand & Coarse sand & Coarse sand \\
\hline
\end{tabular}


resolution). Therefore maximal decrease in the number of taxa tends also to minimize the ratio.

\section{RESULTS}

For each site 435 intermatrix rank correlations were calculated, among all different hierarchical taxonomic levels and with all different types of transformation. The average rank correlation coefficient (over all 435 values at each site) was 0.68 for Cephalonia, 0.81 for Ithaki and 0.75 for Sounion, whereas the minimal values encountered were $0.11,0.34$ and 0.19 , respectively. All the minimal values involved correlations between presence/absence transformed data at high taxonomic levels and non-transformed data at low taxonomic levels.

The 'second stage' MDS ordination plots (Fig. 1) show the interrelationships between the multivariate patterns of each of the 30 similarity matrices obtained through the analysis of macrofaunal abundance data aggregated to different hierarchical taxonomic levels and with different types of transformation. The 'fan patterns' previously found by Olsgard et al. (1997, 1998) were also apparent in the data from all 3 fish farming areas analyzed. In all cases the patterns corresponding to the analysis at the species level were very similar to each other, whereas patterns at the phylum level 'radiated' depending, for the most part, on the type of transformation. In the coarse sediment sites (i.e. Ithaki and Sounion), where the impacts on the seabed were quantitative rather than qualitative (increase of total abundance by an order of magnitude, while higher numbers of species were found at the stations close to the cages), the series of analyses at different taxonomic levels without transformation showed higher similarities between taxonomic levels than all the other series of transformed data. By contrast at the highly impacted silty site of Cephalonia, where the impact was manifested from a qualitative rather than a quantitative standpoint (slight increase in total macrofaunal abundance but low numbers of species at the impacted stations), the non-transformed series showed large dissimilarities between successive hierarchical taxonomic levels. On the other hand, the results obtained through presence/absence transformation seemed to vary considerably at higher taxonomic levels.

The 'information loss' is expressed as a decrease in the rank correlation coefficient of the analysis at higher taxonomic levels in comparison to the analysis at the species level (Fig. 2). Under all types of transformation and for all 3 farming sites the information loss was quite low up to the level of family, the rank correlation coefficient remaining between 0.90 and 0.95 , whereas with further decrease in taxonomic resolution the values of the correlation coefficient decreased substantially depending on the type of transformation. As may be inferred from Fig. 2, the pattern obtained from this type of analysis varied considerably with the type of transformation used. In all cases (except presence/ absence transformation) the curve corresponding to the highly impacted area (Cephalonia) lies below the curves of the 2 coarse-sediment sites, whereas the curve corresponding to the least impacted site (Sounion) is either above (none, square root and 4 th root transformations) or below (log transformation) the curve of the moderately polluted site (Ithaki). Only
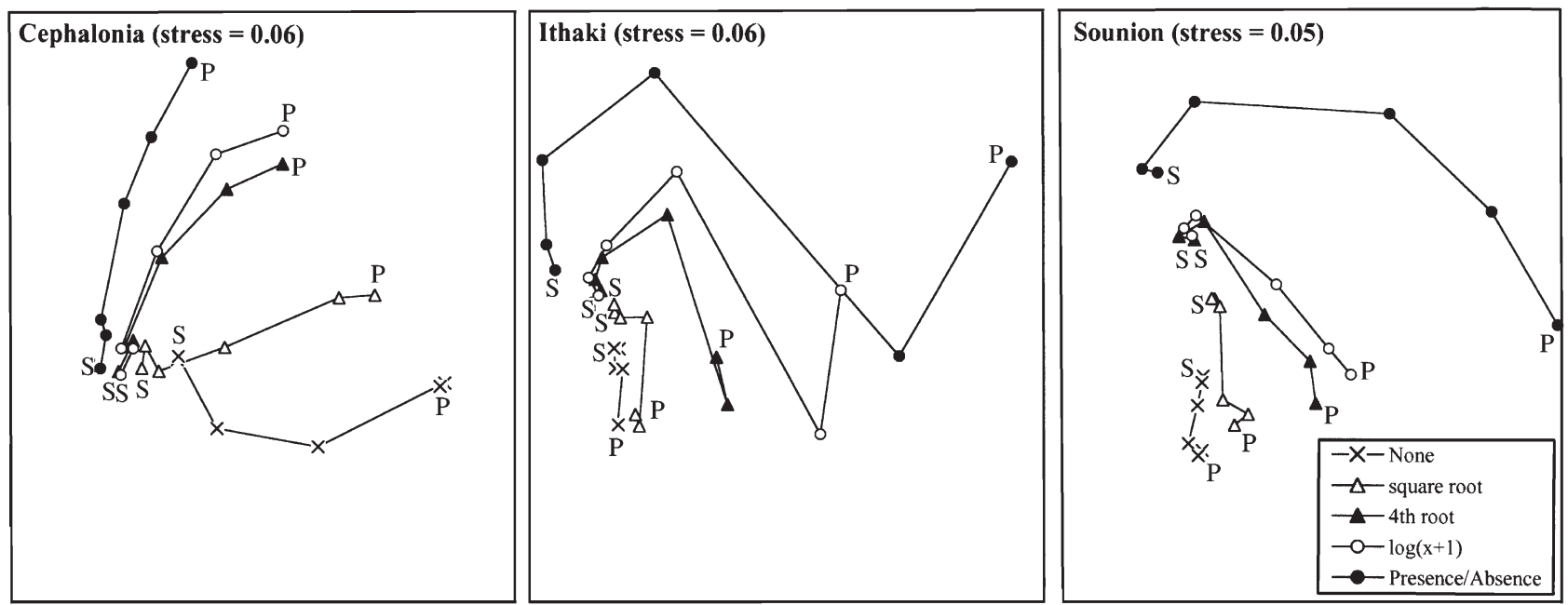

Fig. 1. 'Second stage' multidimensional scaling ordination plots of intermatrix rank correlation for the 3 fish farming sites. For every type of transformation consecutive levels of taxonomic resolution are linked with a line, and the extreme levels are indicated (S: species; P: phylum) 

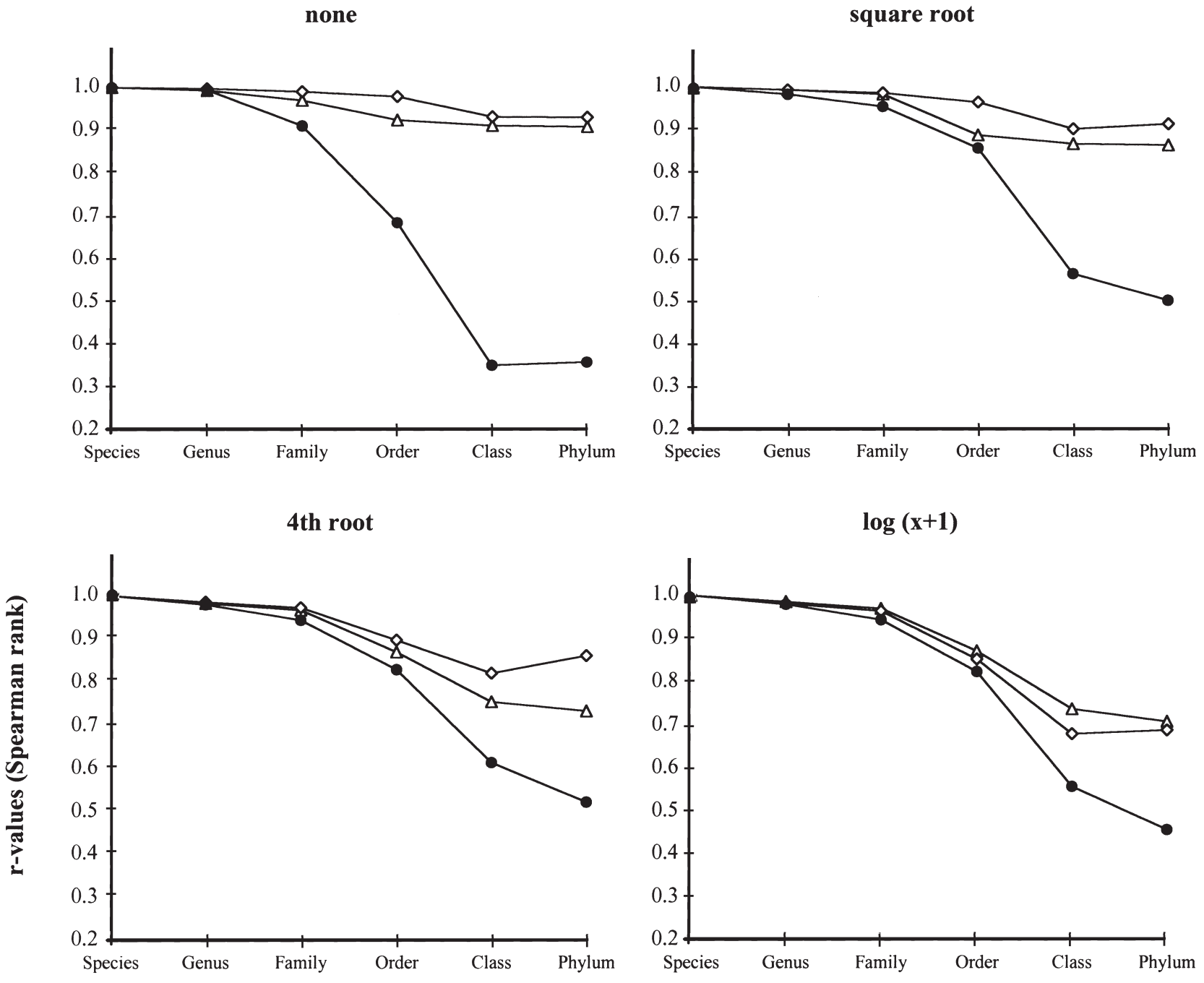

presence / absence

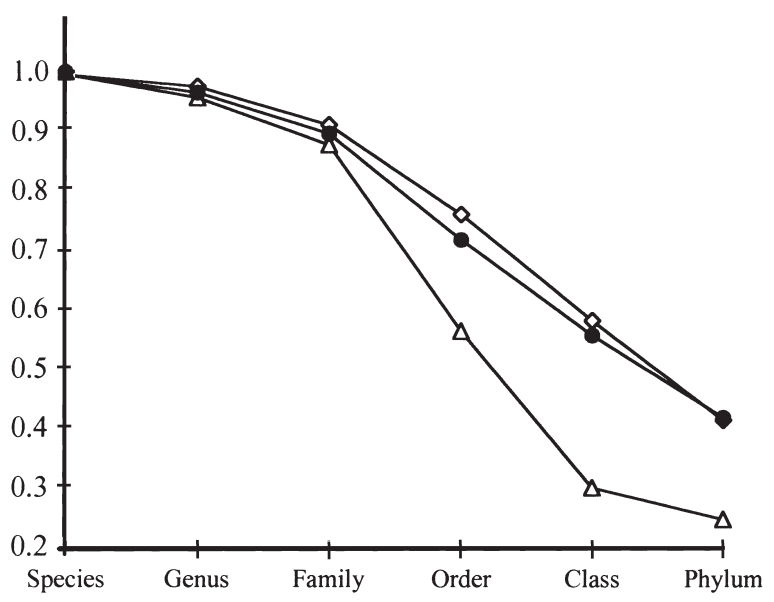

$\neg-$ Sounion

$\multimap$ Ithaki

$\multimap-$ Cephalonia

Taxonomic levels

Fig. 2. Degree of correlation between the underlying faunal similarity matrices for the species level and the matrices for higher taxonomic levels at the 3 fish farms under different types of data transformation 


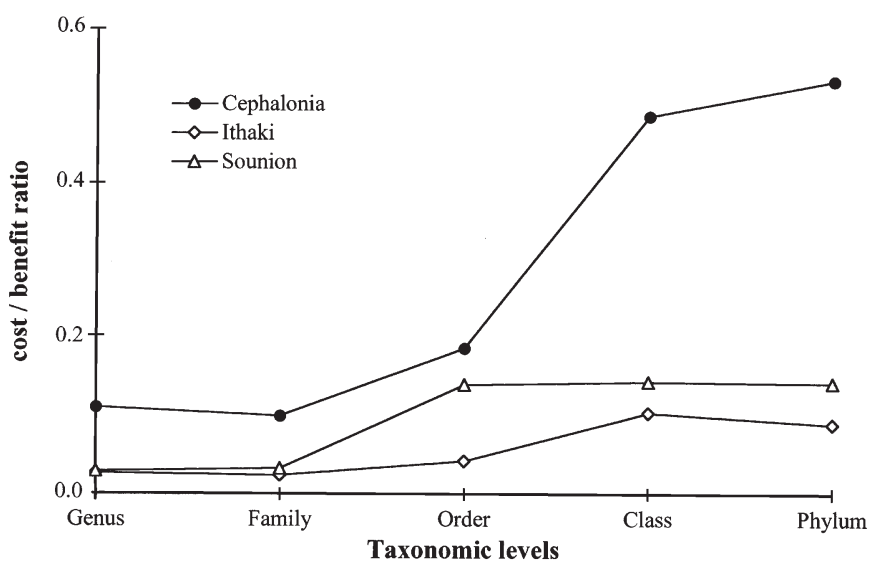

Fig. 3. Cost/benefit analysis for different taxonomic levels for the 3 fish farming sites

presence/absence transformed data showed a pattern which was partly similar to that found by Olsgard et al. (1998).

The cost/benefit ratio analysis for the 3 fish farming areas (Fig. 3) showed minimal values at the level of family, indicating that analysis at this taxonomic level gives the best balance between precision of the results and decrease in taxonomic effort. At the level of genus, although the information loss is quite small (high correlation coefficient with the analysis at the species level), the decrease in taxa is only 15 to $25 \%$ in comparison to the number of species. At higher taxonomic levels the decrease in precision is not compensated by the drastic decrease in the number of taxa.

\section{DISCUSSION}

In the present paper we have compared multivariate patterns obtained through the analysis at the species level to those obtained through the analysis at higher taxonomic levels. It was found that information loss was relatively low as data were aggregated at higher taxonomic levels; this has also been reported for benthic communities subject to different types of disturbance by Warwick (1988a,b), Ferraro \& Cole (1990), Somerfield \& Clarke (1995), Olsgard et al. (1997, 1998) and Rumohr \& Karakassis (1999).

It was also found that the choice of taxonomic level for the analysis of macrofauna and the transformation of the data affected the results obtained by subsequent analysis as was reported by Olsgard et al. $(1997,1998)$. These authors suggested in the latter paper that using a 4 th root transformation is roughly equivalent to reducing abundances to a scale of 0 to 5 ; therefore monitoring could be based on assessing abundance on a crude scale and then using these (untransformed) data. It may not be worth the effort to precisely count the most abundant 'opportunistic' species (7366 Capitella spp. specimens were counted one by one during the analysis of the data sets used in this study), but in most cases it seems essential to determine the numbers of the less abundant species in the community, which actually provides the measure of diversity.

As emphasized by Krebs (1989), the use of data transformation for community comparisons involves 'a considerable amount of judgment' and 'no one strategy can be universally recommended' and much depends on one's research objectives. According to Clarke \& Warwick (1994) 'the choice of transformation is more a biological than a statistical question: which 'view' do we wish to take (shallow or deep), given that there are potentially many different 2-dimensional summaries of this high dimensional data?'

The choice of transformation determines the relative contribution of quantitative and qualitative intersample differences in the final outcome of all types of multivariate analysis. Strong transformations (4th root, log, presence/absence) give little weight to differences in abundance, whereas a weak (square root) transformation or no transformation at all would result in patterns mainly reflecting the differences of the most abundant species.

The succession along gradients of benthic enrichment (Pearson \& Rosenberg 1978), as well as of other types of disturbance, involve both quantitative and qualitative differences, depending on the temporal scales and the intensity of the disturbance. Depending on their position in the gradient 2 samples may: (1) have almost identical species composition but enormous differences in abundance or (2) have smaller or larger differences in species composition. In the former case the use of a weak transformation could produce large dissimilarities, whereas a strong transformation would result in large similarities. This situation is more likely to happen when samples are taken in the transitional zone, where a varying abundance of opportunistic species may be present together with typical representatives of the 'normal' community. The pattern expected to be obtained through MDS highly depends on the sampling strategy, since the MDS 'algorithm places most weight on the large distances' (Clarke \& Warwick 1994).

The above factors seem to be the reason for the differences found between our data and the pattern reported by Olsgard et al. (1998) linking the degree of disturbance to the correlation between the patterns obtained with different levels of taxonomic resolution. In general the pattern observed by Olsgard et al. (1998) is expected to be found in cases where the disturbance gradient is so strong that it induces significant qualitative changes in the faunal composition, 
whereas intermediate disturbance which may result in considerable increase of an 'opportunistic' species could either increase or decrease the correlation. Our data set also contained some differences compared to the data in Olsgard et al. (1998), specifically: (1) the spatial scale employed in our data set was considerably smaller in order to be adjustable to the needs of the particular effect under investigation and (2) both spatial and temporal changes were investigated (although the spatial element was the dominant, i.e. the observed clusters corresponded to distance from the cages).

In the report on the requirements for monitoring of ecological effects of fish farming (GESAMP 1996) it is stated that monitoring of the macrofaunal community structure is 'expensive and requires taxonomic expertise that may not be widely available, but provides evidence for benthic impact'. The results of the present paper support the idea that monitoring data involving higher taxonomic levels should be acceptable for the assessment of ecological impacts on the benthic communities. In other words, the 'taxonomic sufficiency' (Ellis 1985) for monitoring of fish farming impacts on Mediterranean benthos could be set at the level of family. However, as emphasized by previous authors, 'taxonomic sufficiency' should be considered in the framework of the specific objectives in a given study (Ferraro \& Cole 1995, Olsgard et al. 1998), and therefore no general rules should be established for the selection of a taxonomic level without previous documentation of the effects of the decreasing taxonomic resolution on the quality of the results, in different types of communities and on different types of gradients. The cost/benefit index presented here could be used as a criterion for the selection of a taxonomic level with the best balance between information loss and reduction in identification difficulty. For baseline studies, however, it is important to conduct surveys at the species level, as suggested by Olsgard et al. (1998), so that full knowledge is acquired on the pre-impact community composition.

The concept behind the use of the cost/benefit index is that there is a difference in the rate of information loss and in the decrease in the number of taxa present at each level. In this context an abrupt change in information loss or in the number of taxa may identify the optimal level for the macrofaunal analysis. However, it is perhaps worth noting that this index may only be used for selecting 'the second best' taxonomic level since in our approach the 'best taxonomic level' is by axiom the species level.

In this paper we have considered that the species level is the 'best possible level' for the analysis of faunal data. Also, Rumohr \& Karakassis (1999) have expressed reservations on the use of higher taxonomic levels for the rapid assessment or monitoring of biodiversity, since there is no sound scientific paradigm that biodiversity is evenly distributed among all levels of biological organization, although, comparisons at higher taxonomic levels might be necessary when comparing areas with few or no species in common (Olsgard et al. 1998).

Acknowledgements. We would like to thank 4 anonymous reviewers for helpful comments and criticism on the manuscript. This study is part of the Project No. 565 'Interactions of aquaculture and the marine environment' financed by the Greek General Secretariat for Research and Technology in the framework of the second Operational Programme for Research \& Technology.

\section{LITERATURE CITED}

Bray JR, Curtis JT (1957) An ordination of the upland forest communities of southern Wisconsin. Ecol Monogr 27: 325-349

Brown JR, Gowen RJ, McLusky DM (1987) The effects of salmon farming on the benthos of a Scottish sea loch. J Exp Mar Biol Ecol 109:39-51

Clarke KR, Warwick RM (1994) Change in marine communities: an approach to statistical analysis and interpretation. Plymouth Marine Laboratory, Plymouth

Ellis D (1985) Taxonomic sufficiency in pollution assessment. Mar Pollut Bull 16:459

Ferraro SP, Cole FA (1990) Taxonomic level and sample size sufficient for assessing pollution impacts on the Southern California Bight macrobenthos. Mar Ecol Prog Ser 67: 251-262

Ferraro SP, Cole FA (1995) Taxonomic level sufficient for assessing pollution impacts on the Southern California Bight macrobenthos-revisited. Environ Toxicol Chem 14: 1031-1040

Field JG, Clarke KR, Warwick RM (1982) A practical strategy for analysing multispecies distribution patterns. Mar Ecol Prog Ser 8:37-52

GESAMP (IMO/FAO/UnescoIOC/WMO/IEEA/UN/UNEP Joint Group of Experts on the Scientific Aspects of Marine Environmental Protection) (1996) Monitoring the ecological effects of coastal aquaculture wastes. Rep Stud GESAMP 57:1-38

Gowen RJ, Bradbury NB (1987) The ecological impact of salmonid farming in coastal waters: a review. Oceanogr Mar Biol Annu Rev 25:563-575

Iwama GI (1991) Interactions between aquaculture and the environment. Crit Rev Environ Control 21:177-216

Karakassis I, Tsapakis M, Hatziyanni E (1998) Seasonal variability in sediment profiles beneath fish farm cages in the Mediterranean. Mar Ecol Prog Ser 162:243-252

Karakassis I, Hatziyanni E, Tsapakis M, Plaiti W (1999) Benthic recovery following cessation of fish farming: a series of successes and catastrophes. Mar Ecol Prog Ser 184: 205-218

Karakassis I, Tsapakis M, Hatziyanni E, Papadopoulou KN, Plaiti W (2000) Impact of cage farming of fish on the seabed in three Mediterranean coastal areas. ICES J Mar Sci 57 (in press)

Krebs CJ (1989) Ecological methodology. Harper \& Row Publishers, New York 
Olsgard F, Somerfield PJ, Carr MR (1997) Relationships between taxonomic resolution and data transformations in analyses of a macrobenthic community along an established pollution gradient. Mar Ecol Prog Ser 149:173-181

Olsgard F, Somerfield PJ, Carr MR (1998) Relationships between taxonomic resolution, macrobenthic community patterns and disturbance. Mar Ecol Prog Ser 172:25-36

Pearson TH, Rosenberg R (1978) Macrobenthic succession in relation to organic enrichment and pollution of the marine environment. Oceanogr Mar Biol Annu Rev 16:229-311

Pitta P, Karakassis I, Tsapakis M, Zivanovic S (1999) Natural versus mariculture induced variability in nutrients and plankton in the eastern Mediterranean. Hydrobiologia 391:181-194

Rumohr H, Karakassis I (1999) Comparison of multivariate patterns: different taxonomic levels in macrofaunal analy-

Editorial responsibility: Otto Kinne (Editor),

Oldendorf/Luhe, Germany sis versus sediment profiling imagery (SPI). Mar Ecol Prog Ser 190:125-132

Somerfield PJ, Clarke KR (1995) Taxonomic levels in marine community studies, revisited. Mar Ecol Prog Ser 127:113-119

Warwick RM (1988a) The level of taxonomic discrimination required to detect pollution effects on marine benthic communities. Mar Pollut Bull 19:259-268

Warwick RM (1988b) Analysis of community attributes of the macrobenthos of Frierfjord/ Langesundfjord at taxonomic levels higher than species. Mar Ecol Prog Ser 46:167-170

Warwick RM (1993) Environmental impact studies on marine communities: pragmatical considerations. Aust J Ecol 18: $83-80$

Weston DP (1990) Quantitative examination of macrobenthic community changes along an organic enrichment gradient. Mar Ecol Prog Ser 61:233-244

Submitted: August 31, 1999; Accepted: April 18, 2000

Proofs received from author(s): August 28, 2000 